\title{
KERAGAMAN ARTHROPODA PREDATOR PADA TANAMAN PADI DI KECAMATAN TUGUMULYO
}

\section{DIVERSITY OF PREDATORY ARTHROPODS ON RICE PLANTS IN TUGUMULYO SUBDISTRICT}

\author{
Sumini ${ }^{*}$, Samsul Bahri ${ }^{1}$, Hermanto $^{1}$, Sutejo $^{1}$ \\ ${ }^{1}$ Program Studi Agroekoteknologi, Fakultas Pertanian, Universitas Musi Rawas \\ Jl. Sultan Mahmud Badaruddin II, Air Kuti, Lubuk Linggau Tim. I, Kota Lubuklinggau, Sumatera Selatan
}

\begin{abstract}
ABSTRAK
Penelitian ini bertujuan untuk mengevaluasi keragaman arthropoda predator pada tanaman padi di Kecamatan Tugumulyo. Penelitian ini dilaksanakan pada bulan April - Agustus 2018. Metode penelitian yang digunakan adalah metode survei dengan menggunakan metode acak sederhana, dan diambil 4 Desa sebagai tempat pengambilan sampel. Adapun sampel yang dipilih secara acak dengan rincian sebagai berikut: Desa D Tegalrejo, Desa E Wonokerto, Desa H Wukirsari, dan Desa A Widodo. Dari setiap desa ditetapkan 3 petakan sawah dengan luas petakan $10 \mathrm{~m}$ x $10 \mathrm{~m}$. Pengambilan sampel data dilakukan dengan menggunakan jaring serangga pada setiap petakan. Serangga yang didapat dibersihkan dan diidentifikasi di Laboratorium Hama dan Penyakit Fakultas Pertanian Universitas Musi Rawas. Hasil penelitian diketahui bahwa keanekaragaman arthropoda predator yang ditemukan baik di permukaan tanah maupun ditajuk tanaman termasuk ke dalam kriteria sedang dengan indeks keragaman $1<\mathrm{H}^{\prime}<3$. Nilai keanekaragaman di tajuk tanaman dan di permukaan tanah tertinggi di Desa D Tegalrejo yaitu $\mathrm{H}^{\prime}=$ 2,16 dan $\mathrm{H}^{\prime}=2,17$ dengan indeks dominasi yaitu 0,3 pada tajuk tanaman dan 0,5 di permukaan tanah sehingga tergolong rendah.
\end{abstract}

Kata kunci: Kelimpahan, Arthropoda Predator, Padi

\begin{abstract}
This study aimed to evaluate the diversity of predatory arthropods in rice plants in Tugumulyo District. This research was conducted in April - August 2018. The study used an survey method with a simple random sampling, and 4 villages were taken as sampling sites. The samples were randomly selected with the following details: D Tegalrejo Village, E Wonokerto Village, $H$ Wukirsari Village, and A Widodo Village. From each village, 3 plots of rice fields with an area of $10 \mathrm{~m} \times 10 \mathrm{~m}$ were assigned. Sampling of data was carried out using insect nets on each plot. The insects obtained were cleaned and identified at the Pest and Disease Laboratory, Faculty of Agriculture, Musi Rawas University. The results of the research showed the diversity of predatory arthropods found both on the soil surface and in the canopy of plants was included in the moderate criteria with a diversity index of $1<H^{\prime}<3$. The value of diversity in the plant canopy and on the soil surface was the highest in D Tegalrejo Village, namely $H^{\prime}=2.16$ and $H^{\prime}=2.17$ with a dominance index of 0.3 in the plant crown and 0.5 at the soil surface so that it was classified as low
\end{abstract}

Keywords: Abundance, Predatory Arthropods, Rice

\section{Pendahuluan}

Padi (Oryza sativa L) merupakan salah satu tanaman pangan penghasil karbohidrat yang paling banyak diminati dan dijadikan sebagai makanan pokok oleh sebagian besar masyarakat Indonesia, sehingga produktivitas dari tanaman harus terus ditingkatkan. Namun dalam

${ }^{*}$ Penulis Korespondensi.

E-mail: sumini@unmura.ac.id

HP : 081366279004 peningkatannya produksi padi di Kecamatan Tugumulyo Kabupaten Musi Rawas ini sering dihadapkan pada berbagai kendala, salah satunya adalah serangan hama. Dengan tingginya serangan hama menyebabkan masyarakat Kecamatan Tugumulyo selalu melakukan pengendalian dengan menggunakan pestisida kimia, karena dianggap cara ini 
merupakan cara paling efektif dalam membunuh hama dengan cepat, sehingga akan menimbulkan dampak negatif pada lingkungan (Sumini et al., 2019).

Salah satu dampak negatif yang ditimbulkan oleh pengendalian dengan menggunakan pestisida kimia yaitu terbunuhnya serangga-serangga berguna dan musuh alami, sehingga dapat menyebabkan hama-hama menjadi resisten dan akan berkembang dengan cepat, akibatnya dapat menyebabkan penurunan produksi padi. Sejalan dengan penelitian Sumini (2020) bahwa penggunaan pestisida kimia yang tidak bijaksana dan dilakukan secara terus menerus di Kecamatan Tugumulyo dapat menyebabkan hama menjadi resisten dan meningkatnya persentase serangan hama mencapai $75,7 \%$ serta dapat menyebabkan terbunuhnya serangga lain.

Kelompok serangga lain yang ada di ekosistem dapat meliputi serangga predator dan serangga penyerbuk. Serangga predator atau sering disebut sebagai arthropoda predator merupakan serangga yang hidup bebas dan mempunyai peranan dalam menekan populasi serangga hama di suatu agroekosistem. Arthropoda predator merupakan suatu organisme yang memakan atau memangsa suatu organisme lain di agroekosistem untuk melangsungkan kehidupannya dan memenuhi kebutuhan makanannya (Hendrival et al., 2017). Arthropoda predator mempunyai jumlah spesies lebih banyak dibandingkan jumlah spesies dari serangga lainnya dalam suatu ekosistem. Keragaman dan kelimpahan dari arthropoda predator juga berkaitan dengan pola tanam dan vegetasi disekitar pertanaman, serta penggunaan dari pestisida kimia dalam melakukan suatu sistem budidaya tanaman (Tauruslina et al., 2015). Oleh sebab itu mekanisme pengaturan populasi arthropoda di suatu ekosistem perlu dilakukan untuk mencapai pertanian berkelanjutan dan menerapkan sistem pengendalian hama secara terpadu (PHT). Menurut Widiarta et al., (2006), bahwa PHT dapat memperbesar peranan dari musuh alami dan penggunaan pestisida kimia secara rasional. Penelitian ini bertujuan untuk menganalisis dan mengevaluasi keragaman arthropoda predator pada tanaman padi di Kecamatan Tugumulyo Kabupaten Musi Rawas.

\section{Metode Penelitian}

Penelitian menggunakan metode survei yang dilakukan pada tanaman padi yang dilakukan pada 4 desa yang ada di Kecamatan
Tugumulyo Kabupaten Musi Rawas dari bulan April - Agustus 2018, dengan luas sampel yang diamati $10 \mathrm{~m} \times 10 \mathrm{~m}$. Penelitian dimulai dari penetapan wilayah studi dan sampel. Lokasi penelitian dipilih sebanyak empat lokasi yang menjadi kelompok penelitian. Pengambilan sampel data yang dilakukan dengan menggunakan jaring serangga pada setiap sampling yang ditentukan. Serangga yang didapat dalam perangkap dimasukan ke dalam kantong plastik yang telah berisi larutan formalin, kemudian dibersihkan dengan air dan dimasukan ke dalam botol vial yang telah berisi alkohol 75\%. Serangga diidentifikasi di Laboratorium Hama dan Penyakit Fakultas Pertanian Universitas Musi Rawas. Peubah yang diamati dalam penelitian ini adalah populasi musuh alami, kelimpahan dan keanekaragaman musuh alami. Struktur Komunitas arthropoda predator dianalisis dengan menghitung indeks keanekaragaman, indeks kemerataan dan indeks dominasi. Indeks keanekaragaman dihitung dengan menggunakan indeks shannon $\left(\mathrm{H}^{\prime}=-\sum\right.$ $(n i / N)$ ln (ni/N)) dan indeks kemerataan $\left(\mathrm{E}=\mathrm{H}^{\prime} / \mathrm{ln}\right.$ (s)) (Ludwig dan Reynold, 1988). Sedangkan indeks dominasi diukur dengan dengan indeks Berger-Parker $(\mathrm{d}=\mathrm{Nmax} / \mathrm{N})$ (Southwood, 1986).

\section{Hasil dan Pembahasan}

Berdasarkan hasil survei yang telah dilakukan di ke empat Desa yang ada di Kecamatan Tugumulyo Kabupaten Musi rawas, maka diketahui bahwa di Desa D Tegalrejo memiliki jumlah individu dari arthropoda predator tertinggi baik di tajuk pertanaman maupun di permukaan tanah yaitu 318 jumlah individu dengan 21 jumlah spesies (Tabel 1) dan 497 jumlah individu dengan 22 jumlah spesies (Tabel 2).

Tingginya jumlah individu arthropoda predator baik di tajuk tanaman maupun di permukaan tanah di Desa D Tegalrejo dipengaruhi oleh tumbuhan lain yang ada disekitar pertanaman padi, yaitu tanaman sayur kacang panjang, kenikir dan tanaman berbunga lainnya yang banyak tumbuh dan ditanami dipinggir dan sekitar pertanaman padi. Hal ini juga dikemukakan oleh Rahardjo et al., (2018) bahwa habitat disekitar pertanaman mampu mempengaruhi kelimpahan dan keanekaragaman dari suatu arthropoda dan mampu mendukung konservasi dari arthropoda predator. Tumbuhan liar (refugia) yang ada disekitar areal pertanaman padi dapat menjadi habitat alternatif bagi arthropoda, terkhusus bagi perkembangan 
Tabel 1. Jumlah Spesies dan Jumlah Individu Arhtropoda Predator yang Aktif di Tajuk pada Pertanaman Padi di Kecamatan Tugumulyo.

\begin{tabular}{|c|c|c|c|c|c|c|c|c|}
\hline \multirow{2}{*}{ Kelas/Famili } & \multicolumn{2}{|c|}{ Desa A Widodo } & \multicolumn{2}{|c|}{ Desa D Tegalrejo } & \multicolumn{2}{|c|}{$\begin{array}{c}\text { Desa E } \\
\text { Wonokerto } \\
\end{array}$} & \multicolumn{2}{|c|}{$\begin{array}{c}\text { Desa H } \\
\text { Wukirsari } \\
\end{array}$} \\
\hline & $\begin{array}{c}\sum_{\text {Spesies }} \\
\end{array}$ & $\sum_{\text {Individu }}$ & $\begin{array}{c}\sum_{\text {Spesies }} \\
\end{array}$ & $\sum_{\text {Individu }}$ & $\begin{array}{c}\sum_{\text {Spesies }} \\
\end{array}$ & $\sum_{\text {Individu }}$ & $\begin{array}{c}\sum_{\text {Spesies }} \\
\end{array}$ & $\sum_{\text {Individu }}$ \\
\hline \multicolumn{9}{|l|}{ Arachnida } \\
\hline Tettragnathidae & 3 & 109 & 3 & 128 & 3 & 16 & 1 & 7 \\
\hline Aranidae & 1 & 17 & 1 & 6 & 1 & 1 & 0 & 0 \\
\hline Lycosidae & 3 & 8 & 2 & 27 & 2 & 6 & 1 & 2 \\
\hline Linyphiidae & 3 & 13 & 3 & 12 & 3 & 21 & 3 & 6 \\
\hline Oxyophidae & 2 & 10 & 2 & 29 & 2 & 13 & 2 & 5 \\
\hline Salticidae & 1 & 1 & 1 & 2 & 0 & 0 & 1 & 3 \\
\hline \multicolumn{9}{|l|}{ Coleoptera } \\
\hline Carabidae & 1 & 1 & 1 & 3 & 0 & 0 & 0 & 0 \\
\hline Staphylidae & 1 & 6 & 1 & 8 & 1 & 11 & 1 & 10 \\
\hline Coccinelidae & 1 & 23 & 2 & 31 & 1 & 14 & 1 & 5 \\
\hline \multicolumn{9}{|l|}{ Odonata } \\
\hline Coenagrionidae & 1 & 8 & 1 & 10 & 1 & 6 & 1 & 10 \\
\hline Lubellulidae & 1 & 12 & 1 & 15 & 0 & 0 & 1 & 2 \\
\hline \multicolumn{9}{|l|}{ Orthoptera } \\
\hline Tettigonidae & 1 & 6 & 1 & 23 & 1 & 8 & 1 & 5 \\
\hline Gryllidae & 2 & 7 & 1 & 8 & 1 & 6 & 1 & 6 \\
\hline \multicolumn{9}{|l|}{ Hymenoptera } \\
\hline Formicidae & 0 & 0 & 1 & 16 & 1 & 2 & 1 & 1 \\
\hline Total & 21 & 221 & 21 & 318 & 17 & 104 & 15 & 62 \\
\hline
\end{tabular}

Tabel 2. Jumlah Spesies dan Jumlah Individu Arthropoda Predator Penghuni Tanah pada Pertanaman Padi di Kecamatan Tugumulyo.

\begin{tabular}{|c|c|c|c|c|c|c|c|c|}
\hline \multirow[b]{2}{*}{ Kelas/Famili } & \multicolumn{2}{|c|}{ Desa A Widodo } & \multicolumn{2}{|c|}{ Desa D Tegalrejo } & \multicolumn{2}{|c|}{ Desa E Wonokerto } & \multicolumn{2}{|c|}{ Desa H Wukirsari } \\
\hline & $\sum_{\text {Spesies }}$ & $\sum_{\text {Individu }}$ & $\sum_{\text {Spesies }}$ & $\sum_{\text {Individu }}$ & $\sum_{\text {Spesies }}$ & $\sum_{\text {Individu }}$ & $\sum_{\text {Spesies }}$ & $\sum_{\text {Individu }}$ \\
\hline \multicolumn{9}{|l|}{ Arachnida } \\
\hline Lycosidae & 4 & 67 & 4 & 77 & 2 & 20 & 1 & 11 \\
\hline Tetragnathidae & 3 & 28 & 4 & 11 & 2 & 12 & 0 & 0 \\
\hline Linyphiidae & 1 & 18 & 1 & 25 & 1 & 16 & 1 & 9 \\
\hline Oxyophidae & 2 & 41 & 2 & 57 & 1 & 19 & 1 & 6 \\
\hline Araneidae & 1 & 48 & 1 & 30 & 1 & 22 & 1 & 9 \\
\hline Salticidae & 2 & 30 & 2 & 38 & 2 & 27 & 2 & 30 \\
\hline \multicolumn{9}{|l|}{ Coleoptera } \\
\hline Carabidae & 5 & 164 & 5 & 214 & 3 & 102 & 3 & 67 \\
\hline Staphylidae & 1 & 7 & 1 & 8 & 1 & 12 & 1 & 4 \\
\hline \multicolumn{9}{|l|}{ Orthoptera } \\
\hline Gryllidae & 1 & 29 & 2 & 37 & 1 & 13 & 1 & 5 \\
\hline \multicolumn{9}{|l|}{ Hymenoptera } \\
\hline Formicidae & 4 & 139 & 5 & 221 & 3 & 115 & 2 & 79 \\
\hline Total & 20 & 432 & 22 & 497 & 14 & 243 & 11 & 141 \\
\hline
\end{tabular}


Jurnal Ggratech 11 (2) 50-55, Desember 2021

Hasil survei menunjukan bahwa kelimpahan arthropoda predator tertinggi dari kelas arachnida dari famili Tetragnathidae di tajuk tanaman padi (Gambar 1) dan dari famili Lycosidae di permukaan tanah (Gambar 2). Tingginya kelimpahan dari ke dua famili tersebut dapat dipengaruhi dari kondisi dari ketersediaan makanan dan lingkungan di ekosistem pertanaman padi. Setiap jenis hewan

$$
\begin{aligned}
& \text { e-ISSN : 2621-7236 } \\
& \text { p-ISSN : 1858-134X }
\end{aligned}
$$

(serangga) dapat menjadi subjek kerja simultan dari semua faktor yang ada pada lingkungannya (Price et al., 2011). Diketahui bahwa beberapa faktor lingkungan mempunyai pengaruh yang lebih besar dari faktor lainya, sehingga dapat mempengaruhi ambang batas dan kelimpahan dari serangga predator yang ada di ekosistem pertanaman.

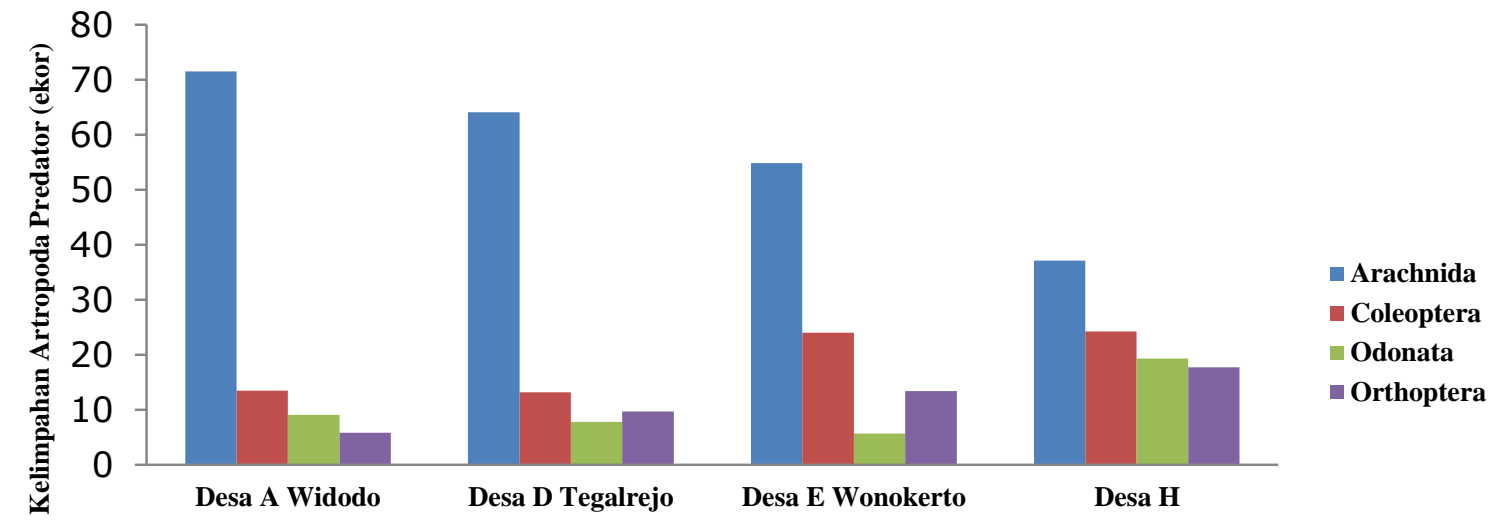

Desa Pengamatan

Gambar 1. Kelimpahan Arthropoda Predator Penghuni Tajuk pada Pertanaman Padi di Kecamatan Tugumulyo

Faktor lingkungan mampu mempengaruhi keberadaan dan kelimpahan serangga predator baik secara langsung maupun tidak langsung. Secara langsung kondisi lingkungan fisik tertentu yang tidak sesuai dengan kehidupan serangga akan langsung mempengarui

keragaman dan kelimpahan dari serangga predator. Dan secara tidak langsung faktor lingkungan akan mempengaruhi kondisi makanan, keberadaan pesaing atau pemangsa lain yang berada di ekosistem pertanaman.

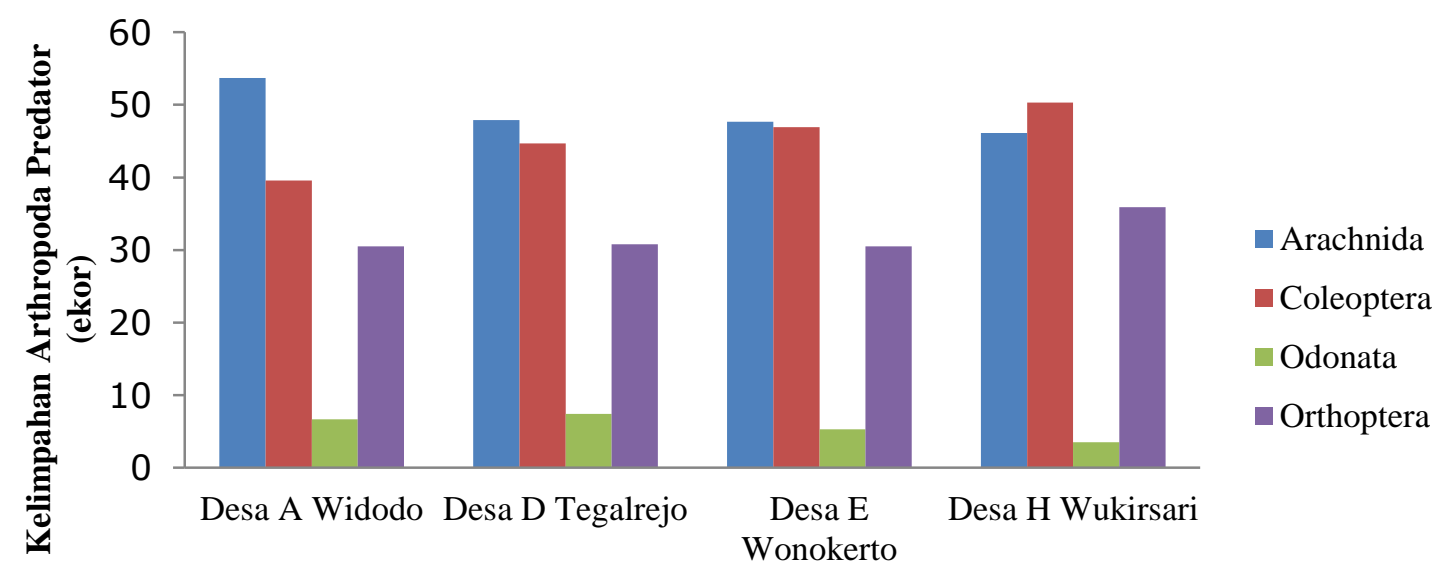

\section{Desa Pengamatan}

Gambar 2. Kelimpahan Arthropoda Predator Penghuni Tanah pada Pertanaman Padi di Kecamatan Tugumulyo

Keanekaragaman arthropoda predator yang ditemukan baik di permukaan tanah maupun ditajuk tanaman termasuk ke dalam kriteria sedang dengan indeks keragaman $1<\mathrm{H}^{\prime}$
< 3. Nilai keragaman ditajuk tanaman tertinggi pada Desa A Widodo yaitu 2,16 dan terendah pada Desa E Wonokerto yaitu 1,56 (Tabel 1), sedangkan di permukaan tanah nilai keragaman 
Tabel 3. Karakteristik komunitas artropoda predator di tajuk tanaman padi di Kecamatan Tugumulyo

\begin{tabular}{lrrrr}
\hline \multirow{3}{*}{ Karakteristik Komunitas } & \multicolumn{4}{c}{ Desa Pengamatan di Kecamatan Tugumulyo } \\
\cline { 2 - 5 } & $\begin{array}{c}\text { Desa A } \\
\text { Widodo }\end{array}$ & $\begin{array}{c}\text { Desa D } \\
\text { Tegalrejo }\end{array}$ & $\begin{array}{c}\text { Desa E } \\
\text { Wonokerto }\end{array}$ & $\begin{array}{c}\text { Desa H } \\
\text { Wukirsari }\end{array}$ \\
\hline Indek Keanekaragaman $\left(\mathrm{H}^{\prime}\right)$ & 2,16 & 1,96 & 1,56 & 1,96 \\
Indeks Dominasi (d) & 0,29 & 0,29 & 0,28 & 0,3 \\
Indeks Kemerataan (E) & 0,93 & 0,85 & 0,68 & 0,85 \\
\hline
\end{tabular}

Keanekaragaman yang sedang menunjukan bahwa penyebaran dari jumlah individu tiap jenis dan kestabilan dari setiap populasi juga sedang. Menurut Hardjosuwarno (1990), menyatakan bahwa indeks keanekagaman $\left(\mathrm{H}^{\prime}\right)$ terdiri dari beberapa kriteria yaitu : Jika H' lebih dari 3,0 menunjukan keragaman yang tinggi, jika nilai H' sebesar 1 1,5 menunjukan keragaman sedang, dan jika nilai $H^{\prime}$ kurang dari 1 maka menunjukan keragaman rendah. Sejalan dengan pendapat Alwi et al., (2020) bahwa suatu komunitas di agroekosistem dapat dikatakan tinggi keanekaragamannya jika komunitas tersebut tersusun dari banyak jenis dengan kelimpahan jenis yang sama atau hampir sama, dan sebaliknya jika suatu komunitas tersebut disusun dari sedikit jenisnya dan sedikit pula jenis yang mendominasi maka keanekaragaman di agroekosistem akan rendah.

Tabel 4.. Karakteristik komunitas artropoda predator di tajuk pada lahan yang diaplikasikan bioinsektisida dan kontrol di sawah lebak.

\begin{tabular}{lrrrr}
\hline \multirow{3}{*}{ Karakteristik Komunitas } & \multicolumn{4}{c}{ Desa Pengamatan di Kecamatan Tugumulyo } \\
\cline { 2 - 5 } & $\begin{array}{c}\text { Desa A } \\
\text { Widodo }\end{array}$ & $\begin{array}{c}\text { Desa D } \\
\text { Tegalrejo }\end{array}$ & $\begin{array}{c}\text { Desa E } \\
\text { Wonokerto }\end{array}$ & $\begin{array}{c}\text { Desa H } \\
\text { Wukirsari }\end{array}$ \\
\hline Indek Keanekaragaman (H') & 2,09 & 2,17 & 1,79 & 2,07 \\
Indeks Dominasi (d) & 0,5 & 0,4 & 0,2 & 0,1 \\
Indeks Kemerataan (E) & 0,82 & 0,85 & 0,78 & 0,87 \\
\hline
\end{tabular}

Indeks dominasi tergolong rendah yaitu $0<\mathrm{C} \leq$ 0,5 karena dalam penelitian ini indeks dominasi yaitu 0,3 pada tajuk tanaman dan 0,5 di permukaan tanah. Nilai indeks dominasi mempunyai kecenderungan mendekati 0 , hal ini dapat dikatakan bahwa tidak ada suatu spesies yang mendominasi, yang artinya pada setiap desa mempunyai kesempatan yang sama dalam memanfaatkan sumberdaya alam yang ada. Dominasi dari suatu spesies tertentu di suatu ekosistem mampu menurunkan indeks kekayaan dari spesies yang ada di dalamnya (Parr dan Gibb 2010).

Tinggi rendahnya keanekaragaman, kemerataan dan dominasi pada setiap desa pengamatan disebabkan oleh faktor lingkungan fisik yang ada pada suatu ekosistem tersebut. Perbedaan lingkungan fisik seperti suhu, kelembaban, dan intesitas cahaya menyebabkan terjadinya perbedaan struktur dari arthropoda predator. Samsuri (2019) mengemukakan bahwa keberadaan serangga predator disuatu ekosistem akan menjadi lebih tinggi struktur habitatnya jika habitat yang ada lebih kompleks dan beragam.

\section{Kesimpulan}

Jumlah individu arthropoda predator yang ditemukan tertinggi di Desa D Tegalrejo di tajuk pertanaman yaitu 318 jumlah individu dengan 21 jumlah spesies dan 497 jumlah individu dengan 22 jumlah spesies di permukaan tanah. Keanekaragaman arthropoda predator yang ditemukan baik di permukaan tanah maupun ditajuk tanaman termasuk ke dalam kriteria sedang dengan indeks keragaman $1<\mathrm{H}^{\prime}<3$. Nilai keanekaragaman di tajuk tanaman dan di permukaan tanah tertinggi di Desa D Tegalrejo yaitu $\mathrm{H}^{\prime}=2,16$ dan $\mathrm{H}^{\prime}=2,17$ dengan indeks dominasi yaitu 0,3 pada tajuk tanaman dan 0,5 di permukaan tanah sehingga tergolong rendah. 
Jurnal Ggratech 11 (2) 50-55, Desember 2021

\section{Daftar Pustaka}

Alwi D, Sandra HI. Muhammad, Herat H. 2020. Keanekaragaman dan Kelimpahan Makrozoobenthos pada Ekosistem Mangrove Desa Daruba Pantai Kabupaten Pulau Morota. Jurnal Enggano. Vol. 5(1): 64-77.

Hardjosuwarno, S., 1990. Dasar-Dasar Ekologi Tumbuhan. Fakultas Biologi UGM. Yogyakarta

Hendrival, Lukmanul Hakim, dan Halimuddin. 2017. Komposisi dan Keanekaragaman Arthropoda Predator pada Agroekosistem Padi. J. Floratek 12 (1): 21-33

Parr CL, Gibb H. 2010. Competition and the role of dominant ants. Di dalam: Lach L, Parr CL, Abbott KL, editor. Ant ecology. Oxford University Press Inc. New York (US): hal 77-96.

Price PW, Denno RF, Eubanks MD, Finke DL, Kaplan I. 2011. Insect Ecology, Behavior, Populations and Communities. Cambridge (GB): Cambridge University Press.

Rahardjo, B. T., Ikawati, S., Prasdianata, M. R., dan Tarno, H. 2018. Research Article Effect of Refugia on Spatial and Temporal Distribution of Arthropods on Rice Agroecosystem (Oryza sativa Linn.). Asian Journal of Crop Science. Vol. 10(3):134-140.

Samsuri. 2019. Keanekaragaman Serangga Hama, Predator dan Parasitoid pada Perkebunan Kopi Seat Ungaran. Agroista. Jurnal Agroteknologi. Vol. 3(1): 64-72.
e-ISSN : 2621-7236

p-ISSN : 1858-134X

Sumini, S., Herlinda, S., dan Irsan, C. 2018. Keanekaragaman Arthropoda di Ekosistem Tanaman Padi Ratun yang Diaplikasikan Bioinsektisida Beauveria bassiana. Prospek Agroteknologi, 7(1): 19-28.

Sumini, S., Bahri, S., \& Holidi, H. 2019. Populasi dan Serangan Walang Sangit di Tanaman Padi Sawah Irigasi Teknis Kecamatan Tugumulyo. Klorofil: Jurnal Penelitian Ilmu-Ilmu Pertanian, 13(2), 6770.

Sumini, S. (2020). Evaluasi dan Pemetaan Wereng Coklat pada Tanaman Padi Sawah di Kecamatan Tugumulyo. Agriculture, 15(1): 10-18.

Sumini dan Samsul Bahri. 2020. Keanekaragaman dan Kelimpahan Musuh Alami di Tanaman Padi Berdasarkan Jarak dengan Tanaman Refugia. Jurnal Agrotek Tropika, 8(1), 177-184.

Tauruslina, A.E., Trizelia, Yaherwandi, \& Hamid, H. 2015. Analisis keanekaragaman hayati musuh alami pada eksosistem padi sawah di daerah endemik dan nonendemik wereng batang cokelat Nilaparvata lugens di Sumatera Barat. Pros. Sem. Nas. Masy. Biodiv. Indon. 1(3): 581-589.

Widiarta N , Kusdiaman K, dan Suprihanto J. 2006. Keragaman Arthropoda pada Padi Sawah dengan Pengelolaan Tanaman Terpadu. Jurnal Hama dan Penyakit Tanaman Tropika. Vol. 6 (2): 61 - 69. 